\title{
The development of a urological cytodiagnosis service and an evaluation of its success
}

\author{
P. N. COWEN \\ From the Department of Pathology, Medical School, Leeds
}

SYNOPSIS Results are given of a year's survey of a urological cytodiagnosis service (229 specimens) in its early stages. A significant degree of success has been obtained in detecting carcinomas of the bladder but bladder papillomata and prostatic and renal carcinomas are not so easily revealed. Other limitations are described.

This department has undertaken non-gynaecological exfoliative cytology studies for the past 10 years on a variety of specimens sent from the Leeds General Infirmary. Annual analysis of records revealed a sudden increase in the number of urine specimens received during the 1966-67 survey year which prompted a detailed review of all the reports on these specimens in order to assess the reliability of the urological part of the cytology service. An appraisal of these findings is made here in order to indicate the degree of success which might be expected following our relatively brief experience.

\section{Methods}

A total of 229 urine specimens were received from the Leeds General Infirmary during the survey year (1 November 1966 to 31 October 1967). The first part of an early morning urine specimen, received within two hours of being voided, was preferred but all specimens were examined in consideration of Crabbe's observation (1961) that malignant cells were still recoverable from untreated urine which had been standing for three days in a warm room. Each specimen consisted of approximately $50 \mathrm{ml}$ of urine and all of it was centrifuged immediately on receipt at $1,500 \mathrm{rpm}$ for five minutes. All but a few drops of the supernatant was pipetted off and any sediment resuspended. A drop of this fluid was transferred to each of two albuminized slides and smeared as for making a blood film. The slides were quickly placed, before drying, in an equal-parts mixture of ethanol and ether for a minimum of 20 minutes for fixing, where they could be safely left for a week or more. These were stained in Harris's haematoxylin (seven to 15 minutes) differentiated in acid-alcohol, blued in $\mathrm{NaHCO}_{3}$, and stained in alcoholic eosin.

Each slide was completely scanned under a $\times 5$ objective and a $\times 40$ was used for detailed examination of individual cells. Non-neoplastic cells which were recognized were epithelial cells, which usually appear as typical squames but which are liable to show considerable variation in size and shape (Seybolt, 1960). They are considered to be transitional cells on account of their origin but the large ones show no morphological features which distinguish them from squamous cells exfoliated from other parts of the body. When these cells were uniform in size with little cytoplasm and formed clumps or sheets the possibility of origin from a papilloma was always considered. The only other non-neoplastic cells which were liable to be present in large numbers were polymorphs. The criterion of malignancy was the presence of cells showing anisocytosis and pleomorphism together with variation in nuclear size and therefore an increased nuclearcytoplasmic ratio in many of them (Fig. 1). Nuclei tended to be hyperchromic and often showed coarse clumping of chromatin but the presence of hyperchromatism was not considered an essential feature since vesicular nuclei were sometimes seen in malignant cells. Depending on these features, the specimen was reported as containing neoplastic cells, no neoplastic cells, or cells suspect of being neoplastic ('positive', 'negative' or 'suspect'). In the case of the positive or suspect reports, an indication was given whether the cells were malignant or whether the appearances suggested origin from a papilloma.

The case notes of all of the patients whose urines had been examined during the survey year were scrutinized at 18 months or more after the cytological examination. 


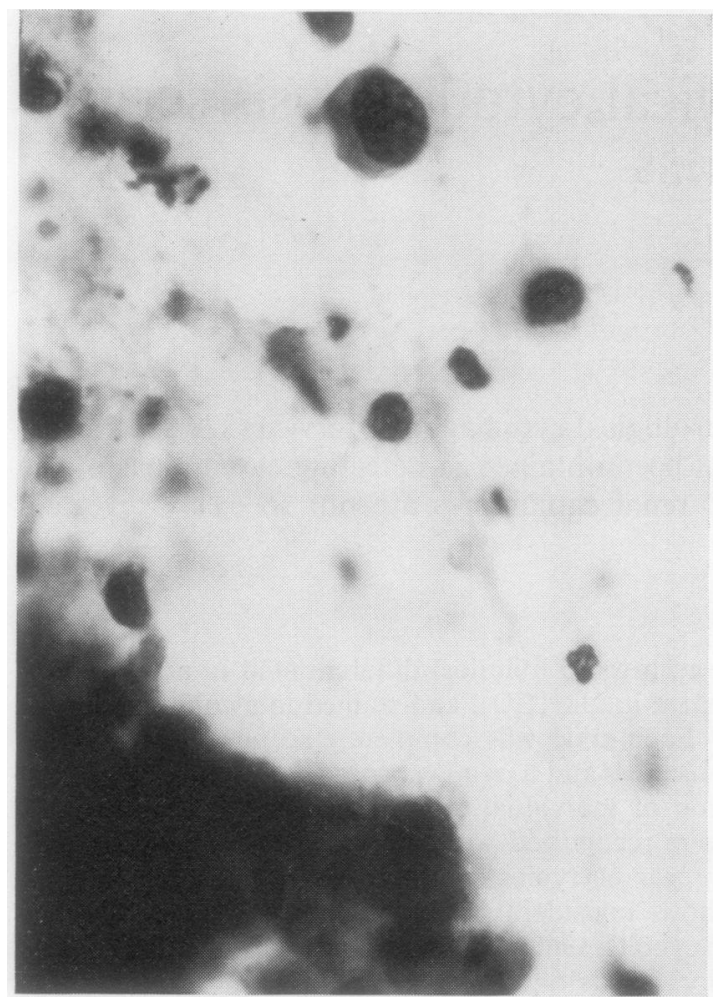

Fig. 1. An example of malignant cells showing size, pleomorphism, anisocytosis, large nuclear-cytoplasmic ratio, and coarse chromatin. A polymorph indicates the size of the cells. (All photomicrographs $\times 710$.)

\section{Results}

Most of the specimens in this survey were single samples although on some occasions several urines were received from the same patient. These multiple specimens had sometimes been received throughout the survey year, during which time papillomas might have arisen, been treated, and then recurred. The result from each specimen is therefore only evaluated in relation to the patient at the time and not in relation to results from other specimens from the same patient.

The number of specimens received during the survey year and how they were reported are shown in Table I.

Twelve of the patients were lost to follow up. They had each contributed one specimen which had been reported negative and although they did not return to the hospital with new growths within at least 18 months, it could not be assumed with certainty that

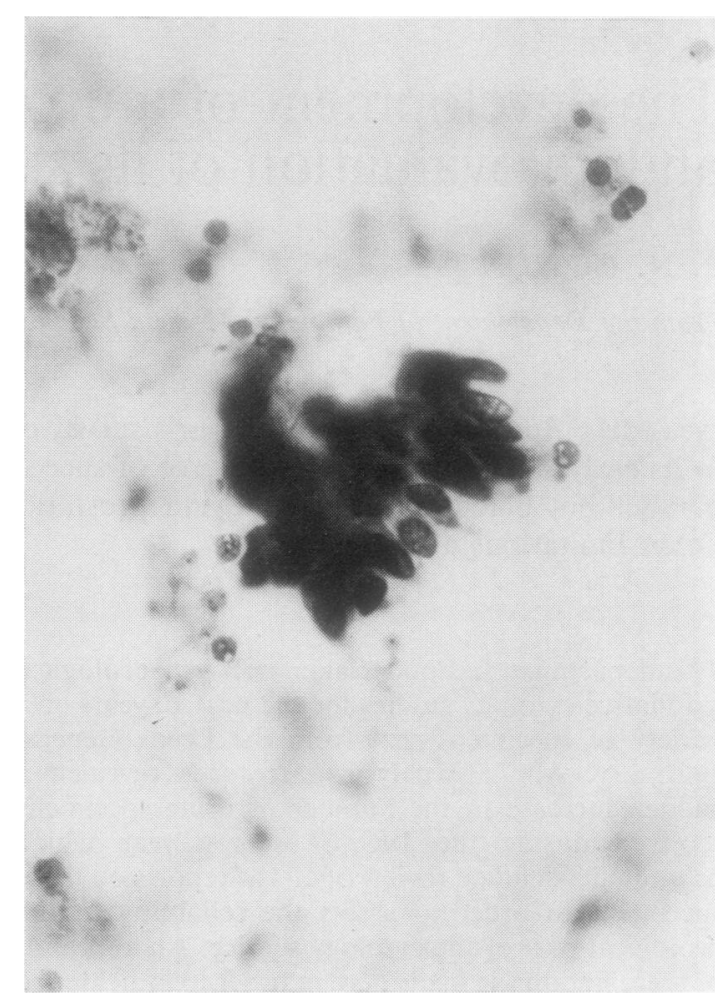

Fig. 2. These cells suggested origin from a new growth but the degree of malignancy was in doubt because of their relative uniformity. In fact, only benign prostatic hyperplasia was present in the patient.

\begin{tabular}{llllllr}
\hline Total urine specimens received & $\ldots$ & $\ldots$ & $\ldots$ & $\ldots$ & $\ldots$ & 299 \\
Number reported positive & $\ldots$ & $\ldots$ & $\ldots$ & $\ldots$ & $\ldots$ & 48 \\
Number reported suspect & $\ldots$ & $\ldots$ & $\ldots$ & $\ldots$ & $\ldots$ & 28 \\
Number reported negative & $\ldots$ & $\ldots$ & $\ldots$ & $\ldots$ & $\ldots$ & 223 \\
\hline
\end{tabular}

Table I Number of specimens received and how reported

a new growth had not been present at the time of the N cytological examination.

\section{POSITIVE REPORTS}

Of the 48 specimens reported positive, 46 were described as showing malignant cells as in Fig. 1, one had cells suggestive of a papilloma, and one had numerous epithelial cells suggestive of a growth of : doubtful malignancy (Fig. 2).

Follow up of these showed that the last two specimens came from tumour-free urinary tracts. The first of these two urines had been reported on the finding of clumps of normal-looking transitional 


\begin{aligned} & \hline No. of Specimens Diagnosis of Patient \\ & \hline 32 Carcinoma of bladder \\ & 7 Papilloma(s) of bladder \\ & 2 Carcinoma of prostate \\ & 5 No growth in the urinary tract \\ & \hline\end{aligned}

Table II Analysis of the 46 positive urines reported to contain malignant cells

cells. The second came from a patient who was suffering from benign prostatic hyperplasia (confirmed at subsequent operation). Analysis of the 46 malignant positive reports is shown in Table II.

The carcinomas varied histologically from relatively well differentiated papillary transitional cell to anaplastic. Some of them were in situ. There was no notable correlation between cytological appearances and degree of anaplasia histologically. The cells seen in urine from the papilloma cases generally showed the same appearance as, and were therefore indistinguishable from, those derived from carcinomas.

Similarly, the cytological appearances in the two urines from the patients with prostatic carcinoma

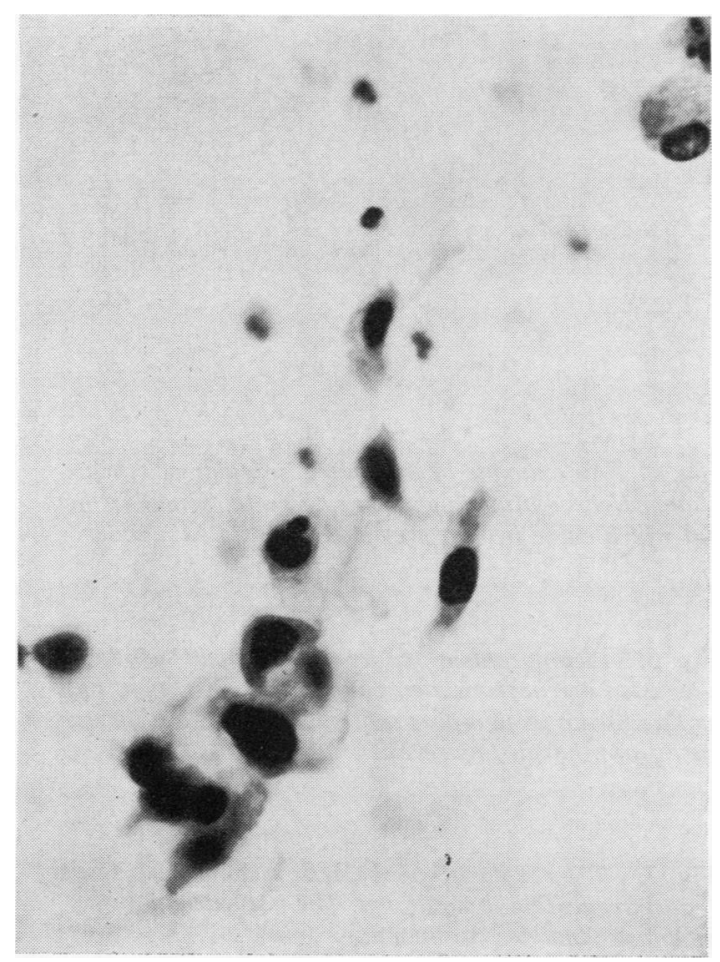

Fig. 3. The pleomorphism and hyperchromasia seen here prompted a report of carcinoma, but these cells came from a papilloma. showed no features which might have distinguished them from bladder carcinoma cells. Figures 3 and 4 show examples of cells derived from a bladder papilloma and prostatic carcinoma respectively.

Of the five urines which came from growth-free patients, three were from patients who had received radiotherapy within the preceding five years (two, five years, and one, three years previously), one was from a patient with benign prostatic hyperplasia, and one urine was very purulent. The malignantlooking cells in the urines from the irradiated and infected bladders were very few in number. Figure 5 shows cells from one of the irradiated bladders and Fig. 6 cells from the urine of the patient who had benign prostatic hyperplasia.

In summary, of the 48 positive reports, 41 of the urines were from carcinomas of bladder, papillomata of bladder, or carcinomas of prostate, and seven were false positives.

\section{SUSPECT REPORTS}

Twenty-eight urine specimens were reported as suspect and 10 of these, on follow up, were found to

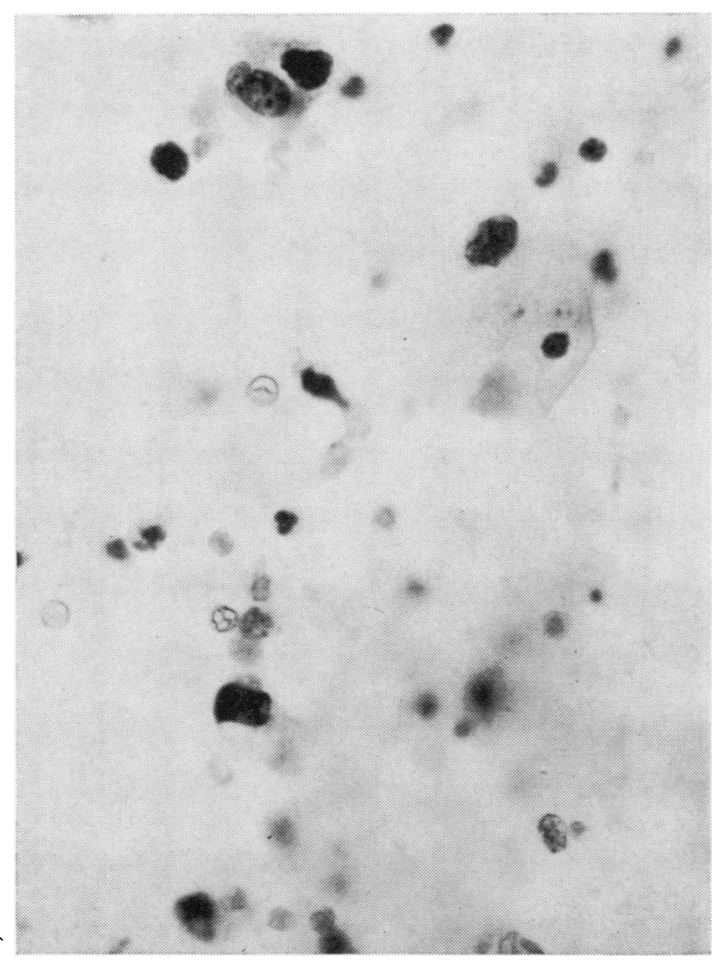

Fig. 4. Features of cells from a prostatic carcinoma. There is nothing to distinguish them from bladder carcinoma cells. 


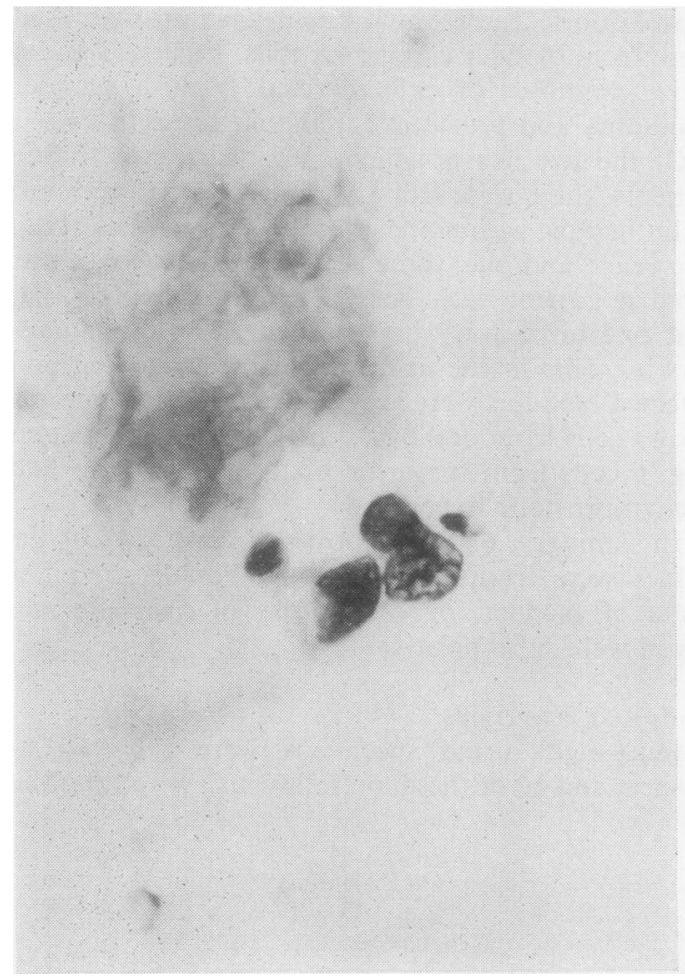

Fig. 5.

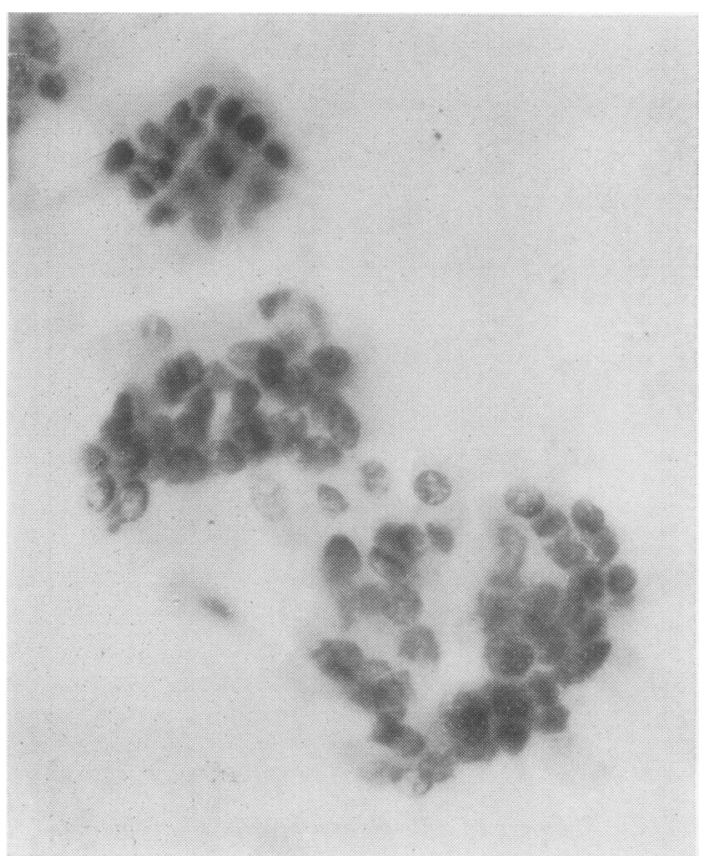

Fig. 7.

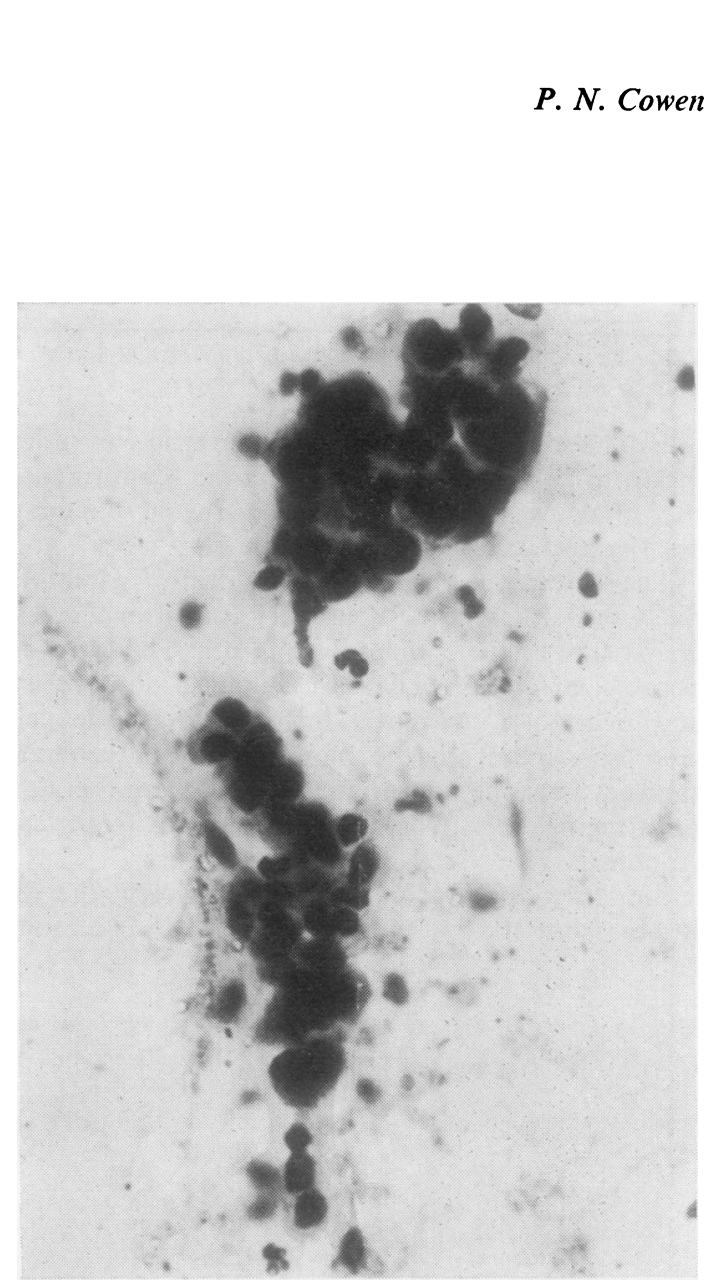

Fig. 6.

Fig. 5. An example of the large, irregular cells with clumped chromatin which suggested a malignant growth but which came from a previously irradiated bladder.

Fig. 6. Pleomorphism and hyperchromasia seen here suggested origin from a carcinoma but the patient only suffered from benign prostatic hyperplasia (a different case from that in Figure 2).

$$
\because
$$

Fig. 7. The regularity of the cells resulted in a suspect rreport suggesting a papilloma. The patient had an anaplastic bladder carcinoma. 
have come from patients in whom a urinary tract growth was present at the time. All were in the bladder; nine were carcinomas and one was a case of multiple papillomata. Review of the slides showed that the reason for the uncertainty which prompted a suspect rather than positive report was cellular distortion in seven of these 10 cases and the presence of only one clump of malignant-looking cells in another. Of the remaining two, one contained many malignant cells which, in retrospect, would have warranted a definite positive report, and the other was considered doubtful because the cells were uniform and suggested no more than possible origin from a papilloma (Fig. 7). In fact, the growth present in the second of these two was an anaplastic carcinoma. The specimen from the patient with multiple papillomata contained one clump of malignantlooking cells and numerous doubtful ones.

Of the 18 urines reported suspect but which came from non-neoplastic urinary tracts, review of the slides showed 13 of them to contain small numbers of distorted cells the appearances of which did not permit the exclusion of malignancy. The remaining five specimens contained numerous transitional cells showing only slight pleomorphism. In two of these specimens there was also considerable cellular degeneration and another was very purulent.

\section{NEGATIVE REPORTS}

Although 223 specimens were reported negative, 12 of the patients (each having contributed one specimen) were lost to follow up, leaving 211 negative reports in this survey. In $\mathbf{1 7 2}$ of them no tumour was subsequently demonstrated, in four, no lesion was found in the bladder on cystoscopy following the cytological report although papillomas developed later, and in one case a nonmalignant ulcer (confirmed histologically and attributable to recent radiotherapy) was present in the bladder in which a carcinoma recurred one year later. These together, therefore, constitute a group of 177 correct negative reports, ie, where no gross neoplasm was present.

The remaining 34 urines came from 27 patients who certaintly or most probably had growths of the urinary tract at the time of the cytological examina-

\begin{tabular}{ll}
\hline No. of Specimens & Diagnosis of Patient \\
\hline 20 & Bladder papillomata (small in 11 cases) \\
1 & Bladder carcinoma \\
7 & Prostatic carcinoma \\
5 & $\begin{array}{l}\text { Renal carcinoma } \\
1\end{array}$ \\
& Bladder invaded by uterine carcinoma not \\
& penetrating bladder mucosa
\end{tabular}

Table III Nature of growths in patients with negative urines but with urogenital tract neoplasms at the time tion. The types of these growths and their numbers are detailed in Table III.

\section{Discussion}

The results of this survey are evaluated on the basis of the summary in Table IV. Seven out of the 48

\begin{tabular}{|c|c|}
\hline $\begin{array}{l}\text { No. of positive reports where growth was present } \\
\text { No. of positive reports where no growth was present }\end{array}$ & $\begin{array}{l}\cdots \\
\cdots\end{array}$ \\
\hline $\begin{array}{l}\text { No. of suspect reports where growth was present } \\
\text { No. of suspect reports where no growth was present } . .\end{array}$ & $\begin{array}{l}\cdots \\
\cdots\end{array}$ \\
\hline $\begin{array}{l}\text { No. of negative reports where growth was present } \\
\text { No. of negative reports where no growth was present }\end{array}$ & $\begin{array}{l}\cdots \\
\cdots\end{array}$ \\
\hline o follow up (all negative reports). . & .. \\
\hline Total number o & .. \\
\hline
\end{tabular}

Table IV Summary of results

urines which were reported to contain neoplastic cells came from patients who had no genito-urinary neoplasm. Of these seven false positives, two of the specimens came from patients with benign prostatic hyperplasia (Figs. 2 and 6). In view of Mason's observation (1964) that normal prostatic epithelial cells have to be distinguished from malignant ones, it is considered likely that the hyperplastic prostate was the source of the misleading cells in these two cases. Three other false positives came from bladders which had received radiotherapy some years previously. Irradiated bladder epithelium can exfoliate malignant-looking cells (Seybolt, 1960; Koss, 1968) but the persistence of these effects, as in the case of the irradiated cervix uteri (Wachtel, 1964; Koss, 1968), has not been described. Although Goodman and Balfour (1964) recognized radiation-induced atypical bladder cells in urine, no features which might distinguish them from malignant cells are indicated, and MacFarlane, Ceelen, and Taylor (1964), who studied urine cytology following radiotherapy for bladder cancer, made no mention of false positives. Nevertheless, the occurrence in this survey of three out of seven false positives from irradiated bladders suggests that the irradiation was responsible. Of the remaining two false positives, one had been reported suggestive of papilloma because of numerous normal transitional cells and the other malignant in view of one malignant-looking clump. In the latter case, numerous pus cells were also present, indicating cystitis which is recognized as a source of atypical cells (Foot, Papanicolaou, Holmquist, and Seybolt, 1958; Umiker, Lapides, and Sourenne, 1962). Four possible reasons for false positive results are thus suggested from this study, namely, benign prostatic hyperplasia, previous irradiation, numerous normal transitional cells, and cystitis. 
Out of th 28 suspect reports, the 18 from tumourfree bladde s contained numerous transitional cells, often atypical due to degeneration, which prompted the suspect report. Similarly, cellular distortion was responsible for a cautious report in the 10 specimens where neoplasia was present.

Thirty-four of the 211 urines reported negative and followed up came from patients who had urinary tract neoplasms. Twenty of the growths were bladder papillomata, seven were prostatic carcinomas, five renal carcinomas, and only one was a bladder carcinoma. The remaining neoplasm was a carcinoma of cervix uteri which had invaded the bladder wall but penetration to the lumen is not recorded. Bladder papillomata are elusive to detection by cytology (Melamed, Koss, Ricci, and Whitmore, 1960; Crabbe, 1961; Umiker, 1964; Kern, Bales, and Webster, 1968). Prostatic carcinomas do not readily exfoliate into urine without prostatic massage (Seybolt, 1960; Cullen, Popham, and Voss, 1967) and renal carcinoma cells are only liable to be found in urine in the late stages of growth (Foot et al, 1958; Umiker, 1964). It is seen from the tables that out of the total of 287 specimens received and followed up, five came from patients with renal carcinomas, none of which were detected, and seven from prostatic carcinomas, two of which were detected. The findings here thus confirm that urine cytology is of much less value in detecting bladder papillomata and renal and prostatic carcinomas than bladder carcinomas. On this basis, only one 'false negative' has occurred in this survey.

The difficulty encountered by histologists in differentiating between benign and malignant bladder papillomata is reflected in the present cytological studies. Pleomorphism of papilloma cells (Fig. 3) led to a diagnosis of carcinoma and cells from a carcinoma-bearing bladder showed features which suggested a papilloma (Fig. 7).

Besides confirming the limitations of urine cytol- ogy described by Foot et al (1958), Voutsa and Melamed (1963), and Umiker (1964), the findings here suggest that caution should be exercised when $\overrightarrow{\vec{F}}$ atypical cells are shed from bladders which havebeen irradiated in the past or when the patient has benign prostatic enlargement.

I thank Mr P. B. Clark and Mr R. E. D. Williams $\stackrel{\mathbb{\curvearrowright}}{\varrho}$ for access to their patients' notes, and Dr C. K. . Anderson for his encouragement and advice.

\section{References}

Crabbe, J. G. S. (1961). Cytology of voided urine with special reference to 'benign' papilloma and some of the problems encountered in.the preparation of smears. Acta cytol. (Philad.), 5, 233-240.

Cullen, T. H., Popham, R. R., and Voss, H. J. (1967). An evaluation of routine cytological examination of the urine. Brit. J. Urol., 39, 615-632.

Foot, N. C., Papanicolaou, G. N., Holmquist, N. D., and Seybolt, J. F. (1958). Exfoliative cytology of urinary sediments. A reviewo of 2,829 cases. Cancer (Philad.), 11, 127-137.

Goodman, G. B., and Balfour, J. (1964). Local recurrence of bladder cancer after supervoltage irradiation. J. Canad. Ass. Radiol., 15,

Kern, W. H., Bales, C. E., and Webster, W. W. (1968). Cytologic $\widehat{\supset}$ evaluation of transitional cell carcinoma of the bladder. J. Urol. (Baltimore), 100, 616-622.

Koss, L. G. (1968). Diagnostic Cytology and Its Histopathologic Bases, 2nd ed., p. 279 and p. 413. Pitman, London.

Mason, M. K. (1964). Cytology of the prostate. J. clin. Path., 17, 581 590.

McDonald, J. R. (1954). Exfoliative cytology in genitourinary and pulmonary diseases. Amer. J. clin. Path., 24, 684-687.

MacFarlane, E. W. E., Ceelen, G. H., and Taylor, J. N. (1964) $\overline{0}$ Urine cytology after treatment of bladder tumors. Acta cytol: (Philad.), 8, 288-292.

Melamed, M. R., Koss, L. G., Ricci, A., and Whitmore, W. F. (1960). Cytohistological observations on developing carcinoma of the urinary bladder in man. Cancer (Philad.), 13, 67-74.

Seybolt, J. F. (1960). Cytology of the urinary tract and prostate. $C A(N . Y), 10,.129-139$.

Umiker, W. (1964). Accuracy of cytologic diagnosis of cancer of the urinary tract. Acta cytol. (Philad.), 8, 186-193.

Umiker, W., Lapides, J., and Sourenne, R. (1962). Exfoliative cytolog of papillomas and intra-epithelial carcinomas of the urinarȳ bladder. Acta cytol. (Philad.), 6, 255-266.

Voutsa, N. G., and Melamed, M. R. (1963). Cytology of in situB carcinoma of the human urinary bladder. Cancer (Philad.), 16, 1307-1316.

Wachtel, E. G. (1964). Exfoliative Cytology in Gynaecological Practice p. 175. Butterworth, London. 